\begin{tabular}{|l|l|l|l|l|l|l|}
\hline InterteXto & Uberaba & UFTM & $\begin{array}{l}\text { v. 3 } \\
\text { n. 1 }\end{array}$ & p. 24-47 & 2010 - jan. / jun. & ISSN 1981-0601 \\
\hline
\end{tabular}

\title{
ALINE, GÊNEROS E LEITURA: POR NOVOS PARADIGMAS DE ENSINO PARA O GÊNERO TIRINHA NO ENSINO BÁSICO
}

\section{ALINE, GENDER AND READING: FOR NEW EDUCATIONAL PARADIGMS FOR GENDER COMIC STRIPS ON THE PRIMARY}

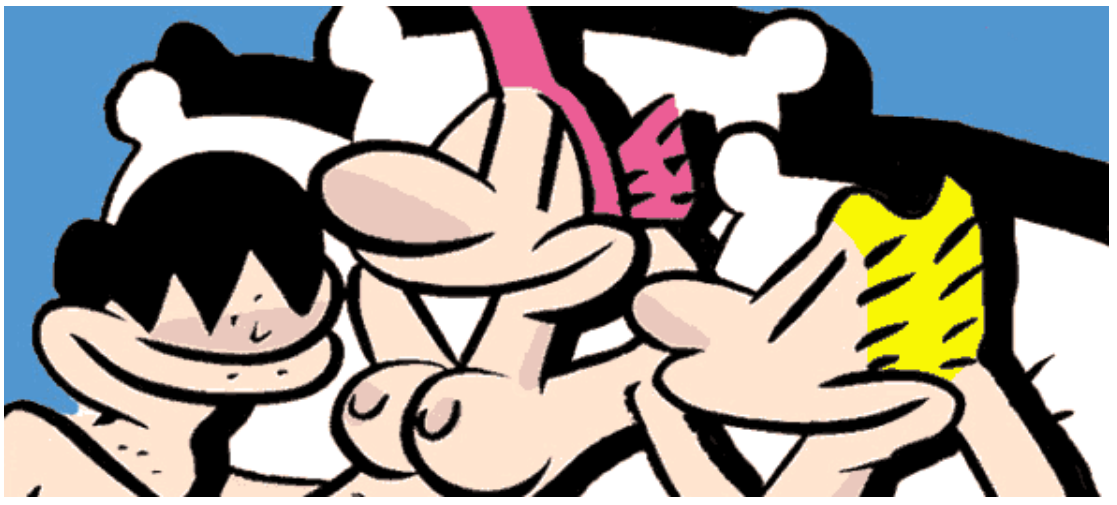

Alex Caldas Simões ${ }^{1}$

Resumo: Os PCN's e o CBC-MG propõem que o ensino de língua materna tenha por ênfase o estudo da linguagem, levando-se em conta a multiplicidade de gêneros discursivos, que orientam produtores e receptores na produção/compreensão de textos orais/escritos de qualquer natureza. Tal demanda educativa, portanto, pressupõe a elaboração de novas estratégias de ensino que contemplem as atuais orientações pedagógicas pautadas no ensino da leitura e da produção de gêneros diversos. Com base nessas orientações, em março de 2009, o MEC incluiu no acervo de livros didáticos das escolas públicas brasileiras 27 títulos de histórias em quadrinhos através do Programa Nacional Biblioteca na Escola. Em nossa exposição, portanto, pautados principalmente nas sugestões de ensino de leitura de Pietri, pretendemos apresentar uma estratégia de ensino para o gênero tirinha que leve em consideração a leitura como atividade complexa dependente da decodificação do leitor e do processo de interação entre leitor e escritor. A partir de um corpus composto por 20 tirinhas de Aline - da série "Aline Gorda" -, do cartunista Adão Iturrusgarai, observaremos, portanto, como ensinar a leitura e a escrita de gêneros discursivos multimodais pode ser produtivo e instigante para o ensino de língua materna no Ensino Básico.

Palavras-chave: Gêneros Discursivos; Tirinha; Estratégias de ensino; Leitura.

Abstract: The PCN's and the CBC-MG propose that the teaching of mother tongue

\footnotetext{
${ }^{1}$ Mestrando em Letras pela Universidade Federal de Viçosa (UFV/Bolsista CAPES/REUNI). Email: axbr1@yahoo.com.br
} 


\begin{tabular}{|l|l|l|l|l|l|l|}
\hline InterteXto & Uberaba & UFTM & $\begin{array}{l}\text { v. 3 } \\
\text { n. } 1\end{array}$ & p. 24-47 & 2010 - jan. / jun. & ISSN 1981-0601 \\
\hline
\end{tabular}

has the emphasis on the study of language, taking into account the multiplicity of genres that guide producers and receivers in the production/comprehension oral/writings of any kind. This educational demand, therefore, presupposes the development of new teaching strategies that address the current educational guidelines for teaching guided reading and production of various genres. Based on these guidelines in March 2009 the MEC included in the collection of textbooks in public schools in Brazil 27 titles of comics through the National School Library Program. In our discussion, therefore, which are primarily based on suggestions for teaching reading Pietri, we will present an education strategy for the comic genre that takes into account the reading as a complex activity-dependent decoding of the reader and the process of interaction between reader and writer. From a corpus consisting of 20 strips Aline the series "Fat Aline" - the of cartoonist Adam Iturrusgarai, we observe, therefore, how to teach reading and writing multimodal genres can be productive and exciting for the teaching of mother tongue in Primary Education.

Key-words: Genres; Comic Strip; Teaching strategies; Reading.

\section{Pressupostos}

As atuais legislações educacionais, tais como os Parâmetros Curriculares Nacionais (PCN's - 1998) de Língua Portuguesa e os Conteúdos Básicos Comuns de Minas Gerais (CBC-MG - 2005), indicam que o ensino atual deve se ater ao estudo do texto materializado em algum gênero discursivo.

Para Bakhtin (2000) gênero discursivo corresponde a um "enunciado relativamente estável" advindo de uma esfera social específica de comunicação que é estruturada por um conteúdo (temático), por um estilo verbal (léxico, frase, gramática) e por uma construção composicional que lhe são próprias. $O$ autor classifica os gêneros discursivos em: primários e secundários. Os primários são os gêneros formados em situações de comunicação espontânea; já os secundários são os gêneros complexos advindos dos gêneros primários (geralmente escritos). Assim, Bakhtin (2000) enfatiza a natureza do enunciado e a sua problemática de correlação entre as categorias de língua, ideologias e visões de mundo - o que distancia o seu estudo de categorias analíticas formalistas, que levam à abstração e ao desvirtuamento da historicidade.

Corroborando com o autor, Todorov (1980) enfatiza que os gêneros são 


\begin{tabular}{|l|l|l|l|l|l|l|}
\hline InterteXto & Uberaba & UFTM & $\begin{array}{l}\text { v. 3 } \\
\text { n. } 1\end{array}$ & p. 24-47 & 2010 - jan. / jun. & ISSN 1981-0601 \\
\hline
\end{tabular}

formados e agrupados por propriedades discursivas específicas que funcionam como "horizontes de expectativa" para os leitores e "modelos de escritura" para os autores, o que acaba por configurar um sistema genérico que é apreendido por sistemas formais ou informais de ensino.

Quanto à funcionalidade e importância dos estudos de gêneros discursivos, Charles Bazerman (2006b) afirma que estudar gêneros é uma forma de compreender que textos geram fatos sociais²; estes só se realizam por meio de gêneros, que se organizam em torno de um conjunto de gêneros ${ }^{3}$ contidos em um complexo sistema de gêneros ${ }^{4}$ que fazem parte, por sua vez, de um grande sistema de atividades humanas ${ }^{5}$. Dessa forma, é o conjunto de repertórios de gêneros comunicativos, segundo o autor (2006b), que organizam a nossa vida social. Estudar gêneros, então, é compreender como as práticas discursivas, profissionais e sociais são produzidas de forma bastante distinta e reconhecível. "O gênero, uma vez estabelecido, torna-se um ambiente estruturado para a escrita e para a leitura, que, por sua vez exerce influência sobre outros aspectos do trabalho profissional" (BAZERMAN, 2006b, p. 60). Estudar gêneros também é compreender "os múltiplos fatores sociais e psicológicos com os quais os enunciados precisam dialogar para serem mais eficazes" (BAZERMAN, 2006a, p. 29).

Diante deste panorama, podemos perceber que unir o estudo de

\footnotetext{
${ }^{2}$ Fato social, segundo o autor, "são coisas que as pessoas acreditam que sejam verdadeiras e, assim, afetam o modo como elas definem uma situação" (BAZERMAN, 2006b, p. 23), ou seja, são ações significativas realizadas pela linguagem.

${ }^{3}$ Conjunto de gêneros é definido por Bazerman como uma "coleção de tipos de textos que uma pessoa num determinado papel tende a produzir" (2006b, p. 32).

${ }^{4}$ Bazerman compreende sistemas de gêneros como "os diversos conjuntos de gêneros utilizados por pessoas que trabalham juntas de uma forma organizada, e também as relações padronizadas que se estabelecem na produção, circulação e uso desses documentos (2006b, p. 32).

${ }^{5}$ Os sistema de gêneros, segundo Bazerman, fazem parte de um sistema de atividades humanas. "Ao definir o sistema de gêneros em que as pessoas estão envolvidas, você identifica também um frame que organiza o seu trabalho, sua atenção e suas realizações" (2006b, p. 33). Podemos entender Sistema de atividades humanas, portanto, segundo o autor (2006b) como os frames citados a pouco.
} 


\begin{tabular}{|l|l|l|l|l|l|l|}
\hline InterteXto & Uberaba & UFTM & $\begin{array}{l}\text { v. 3 } \\
\text { n. } 1\end{array}$ & p. 24-47 & 2010 - jan. / jun. & ISSN 1981-0601 \\
\hline
\end{tabular}

gêneros com o ensino corresponde a uma prática discursiva relevante para o ensino/aprendizagem dos alunos, afinal:

[o]s estudos dos gêneros são necessários exatamente porque não compreendemos os gêneros e as atividades de áreas nãofamiliares que são importantes para nós e para os nossos alunos. Até mesmo aqueles sistemas de gêneros e de atividades com os quais estamos, até certo ponto, mais familiarizados, podem ser submetidos a análises adicionais, de modo que possamos agir de forma mais eficaz e precisa, com uma noção mais articulada do que está acontecendo (BAZERMAN, 2006b, p. 36-37).

Bazerman (2006a) acredita que o melhor gênero para o ensino dependerá de uma negociação entre as instituições, o professor e os alunos. Atualmente, percebe-se que o governo brasileiro tem incentivado práticas de ensino que se formam a partir dos gêneros discursivos; nesse sentido destacamos aqui um gênero em particular: o gênero histórias em quadrinho ${ }^{6}$.

Em março de 2009, conforme indica a reportagem de Rachel Bonino à revista Educação $n^{\circ} 144$, o MEC incluiu no acervo de livros didáticos das escolas públicas brasileiras 27 títulos de histórias em quadrinho através do Programa Nacional Biblioteca na Escola (PNBE): em 2007 foram incluídos na lista do programa 14 títulos de histórias em quadrinho; em 2008 foram incluídos mais 16 títulos; e em 2009 foram incluídos mais 27.

"O que se vê é uma formalização desse gênero textual [histórias em quadrinho] no ambiente escolar, que já tinha seu emprego reconhecido pela Lei de Diretrizes e Bases (LDB) e pelos Parâmetros Curriculares Nacionais (PCN)" (BONINO, 2009, p. 43).

Podemos perceber que há muito tempo o gênero histórias em quadrinho deixou de ser visto como leitura de cunho estritamente infantil e recreativa, uma vez que reflete e padroniza práticas sociais, e, por isso, tem sido visto pelo

\footnotetext{
${ }^{6}$ Tomaremos aqui o termo histórias em quadrinhos como propõe Paulo Ramos (2009) como um hiper-gênero, que corresponde em um grande rótulo que agregaria diferentes gêneros tais como tirinhas, charges, cartuns, entre outros.
} 


\begin{tabular}{|l|l|l|l|l|l|l|}
\hline InterteXto & Uberaba & UFTM & $\begin{array}{l}\text { v. 3 } \\
\text { n. } 1\end{array}$ & p. 24-47 & 2010 - jan. / jun. & ISSN 1981-0601 \\
\hline
\end{tabular}

governo brasileiro como uma forma de instigar e incrementar as práticas pedagógicas contemporâneas.

Segundo Paulo Ramos (2009), hoje, os quadrinhos estão nas provas de vestibular, nas indicações dos PCN's e em programas públicos, como o já referido PNBE. Essas ações, portanto, aproximaram os quadrinhos do ensino, da sala de aula e da realidade pedagógica do professor. Entretanto, o estudo científico dos quadrinhos ainda é pequeno, conseqüência, segundo Ramos (2009, p. 14), "de um histórico preconceituoso sobre o tema, inclusive dentro da universidade".

Ao se referir a este aspecto, Scott McCloud (1995, p. 3) argumenta que a expressão "histórias em quadrinhos" foi por muito tempo vista como algo negativo, como "material de consumo infantil, com desenhos ruins, barato e descartável" - tanto era que os seus artistas tinham vergonha de admitir que produziam histórias em quadrinho, e, por isso, preferiam ser conhecidos como ilustradores e não como cartunistas. Com uma imagem tão negativa sobre o gênero histórias em quadrinho é compreensível analisar o porquê esse gênero discursivo nunca mereceu tanto destaque na escola e na academia; afinal, se este gênero era tão mal configurado o que os nossos alunos poderiam aprender com ele, ou através dele?

Essa visão, entretanto, como argumentamos, não é mais a mesma: atualmente, surge no cenário educativo, novos letramentos ${ }^{7}$ e a necessidade de compreender os textos com suas imagens como construções textuais complexas que refletem e constroem a sociedade atual.

Apesar deste incentivo e necessidade, muitos professores ainda encontram dificuldades em trabalhar esse gênero em sala de aula, como afirma, em reportagem à revista da Educação (2009, p. 44), Waldomiro Vergueiro, coordenador do núcleo de Histórias em Quadrinho da Escola de

\footnotetext{
${ }^{7}$ Podemos entender letramento como "[...] o resultado da ação de ensinar ou de aprender a ler e escrever: o estado ou a condição que adquire um grupo social ou um indivíduo como conseqüência de ter-se apropriado da escrita" (SOARES, 2004, p. 18).
} 


\begin{tabular}{|l|l|l|l|l|l|l|}
\hline InterteXto & Uberaba & UFTM & $\begin{array}{l}\text { v. 3 } \\
\text { n. } 1\end{array}$ & p. 24-47 & 2010 - jan. / jun. & ISSN 1981-0601 \\
\hline
\end{tabular}

Comunicação e Artes da USP.

Diante desse paradigma de ensino, apresentaremos em nossa exposição uma sugestão de ensino que articule o estudo do gênero discursivo tirinha - em um corpus composto por 20 tirinhas da personagem Aline do cartunista Adão Iturrusgarai - com a leitura, como propõe Emerson Pietri (2007).

\section{O gênero tirinha enquanto recurso genérico e de leitura: algumas estratégias}

\section{1 - Pressupostos teóricos}

Antes de apresentarmos as nossas estratégias de ensino de leitura referentes ao gênero tirinha e à leitura no Ensino Básico, fazemos aqui algumas observações. Primeiramente cabe-nos dizer que o ensino de leitura, como indica os postulados da Lingüística Textual, pode privilegiar a leitura enquanto decodificação, processo cognitivo ou interação. Podemos entender:

i) a leitura enquanto decodificação como uma atividade que consiste em dar sentido a cada palavra no texto - é o processo de leitura mais próximo do código lingüístico. Seria como se consultássemos - no dicionário ou no próprio texto - os sentidos de cada palavra materializada em nossa frente e também as relações das palavras entre si.

ii) a leitura enquanto processo cognitivo se pauta no leitor, em seu conhecimento de mundo - advindo de sua vida cotidiana ou do estudo de algum conhecimento científico.

iii) a leitura enquanto interação pressupõe que a construção dos sentidos do texto não é dada, mas construída (Cf. $\mathrm{KOCH}, 2006$ ). Aqui os interlocutores (produtor/leitor) são sujeitos ativos que 


\begin{tabular}{|l|l|l|l|l|l|l|}
\hline InterteXto & Uberaba & UFTM & $\begin{array}{l}\text { v. 3 } \\
\text { n. 1 }\end{array}$ & p. 24-47 & 2010 - jan. / jun. & ISSN 1981-0601 \\
\hline
\end{tabular}

dialogam na construção dos sentidos do texto, afinal qualquer texto possui muitos implícitos que devem ser resolvidos ao se observar a superfície e a organização do texto, e, também, ao se considerar os conhecimentos de mundo partilhados entre os sujeitos da interação.

Para Koch (2006) cada modelo de leitura reflete um conceito específico de língua ${ }^{8}$, sujeito ${ }^{9}$ e texto $^{10}$, como podemos observar nas correlações conceituais na tabela abaixo (Tabela 1):

\begin{tabular}{|l|l|l|l|l|}
\hline Conceitos & Língua & Sujeiło & Texło & Leiłura \\
\hline 1 & $\begin{array}{l}\text { Representação } \\
\text { do pensamento }\end{array}$ & Psicológico & $\begin{array}{l}\text { Produto lógico } \\
\text { do pensamento }\end{array}$ & $\begin{array}{c}\text { Como processo } \\
\text { (leitor) }\end{array}$ \\
\hline 2 & Código & $\begin{array}{l}\text { Pré- } \\
\text { determinado }\end{array}$ & $\begin{array}{l}\text { Produto de } \\
\text { decodificação }\end{array}$ & $\begin{array}{c}\text { Como } \\
\text { decodificação } \\
\text { (texto) }\end{array}$ \\
\hline 3 & Interação & Psicossocial & $\begin{array}{l}\text { Lugar de } \\
\text { interação }\end{array}$ & $\begin{array}{l}\text { Como interação } \\
\text { (leitor e texto) }\end{array}$ \\
\hline
\end{tabular}

(TABELA 1 - Inter-relações entre os conceitos de língua, sujeito e texto; adaptado dos conceitos de Koch (2006, p.16). A inserção dos modelos de leitura é nossa).

Diante desse panorama já bastante conhecido pelos estudiosos da leitura, Moita Lopes (1996) apresenta em suas pesquisas uma pequena revisão

\footnotetext{
${ }^{8}$ Koch (2006) define em suas pesquisas três orientações teóricas para o conceito de língua: i) língua como representação do pensamento; ii) língua como estrutura (código); ou iii) língua como interação.

${ }^{9}$ Koch (2006) define em suas pesquisas três orientações teóricas para o conceito de sujeito: i) sujeito psicológico, aquele que é plenamente consciente do uso de sua linguagem; ii) sujeito pré-determinado (assujeitado), aquele que é reflexo ideológico-discursivo de uma instituição; iii) sujeito psicossocial, aquele que participa da construção dos sentidos do texto.

${ }^{10}$ Koch (2006) define em suas pesquisas três orientações teóricas para o conceito de texto: i) texto como produto lógico do pensamento, onde cabe ao leitor/ouvinte apenas captar o sentido do texto; ii) texto como produto de codificação, onde o leitor/ouvinte apenas decodifica o material textual dado; iii) texto como lugar de interação, onde os sujeitos parceiros da interação constroem e são construídos pelo texto.
} 


\begin{tabular}{|l|l|l|l|l|l|l|}
\hline InterteXto & Uberaba & UFTM & $\begin{array}{l}\text { v. 3 } \\
\text { n. } 1\end{array}$ & p. 24-47 & 2010 - jan. / jun. & ISSN 1981-0601 \\
\hline
\end{tabular}

teórica dos principais modelos de leitura ${ }^{11}$, centrando-se nas teorias de leitura interacionistas $^{12}$, e, também apresenta algumas estratégias de didáticas para 0 ensino de leitura, seja em língua materna ou estrangeira. Sua proposta, que resgataremos em nosso estudo, consiste na construção de estratégias simples - como a construção e verificação de hipóteses sobre um título, imagem ou outro - para que o aluno perceba o texto por meio de um processo perceptivo e por meio de um processo cognitivo de construção de significados, o que potencializará o seu aprendizado e a compreensão do material textual apresentado (no nosso caso o gênero tirinha).

Outra contribuição pertinente para a construção de estratégias didáticas, que privilegiam a utilização de estratégias de leitura com os gêneros discursivos no Ensino Básico, é apresenta por Pietri (2007). O autor (2007) apresenta e discute duas concepções de leitura distintas: a que enfoca o leitor e seus aspectos cognitivos no desenvolvimento e processamento da leitura e de compreensão de textos; e, a que enfoca o texto, em sua produção, distribuição e papel social. Em nossas estratégias de ensino, portanto, nos basearemos também em seus pressupostos. Segundo o autor (2007)

o trabalho com o texto [quaisquer] em sala de aula consiste em mostrar seletivamente as partes que o constituem e com base nesse jogo de esconder e revelar, realizar a elaboração e a verificação de hipóteses (PIETRI, 2007, p. 60).

Sua estratégia, então, pretende ativar gradativamente os conhecimentos

\footnotetext{
${ }^{11}$ Apesar da pretensão do autor, podemos considerar que quando o mesmo (1996, p. 151) ao abordar os tipos de conhecimento (sistêmico e esquemático) simplifica a discussão de forma reducionista, afinal um conhecimento cognitivo não se relaciona, como apresenta Koch \& Travaglia (2006) em seu livro a Coerência Textual, somente com os esquemas, mas também pelos frames, planos, scripts e superestruturas que, em se tratando da Lingüística Textual, não devem ser tomadas como sinônimos.

${ }_{12}$ Moita Lopes (1996) identifica em seus estudos três modelos de leitura: a) modelo de fluxo ascendente, aquele identificado pelas teorias de decodificação (processo preceptivo); b) modelo de fluxo descendente, aquele centrado nas contribuições do leitor para o ato de ler (processo cognitivo); e c) modelo de fluxo ascendente/descendente, aquele centrado tanto no processo perceptivo quanto no processo cognitivo de leitura, onde o significado do texto é negociado na interação leitor-escritor por meio do material lingüístico materializado dado.
} 


\begin{tabular}{|l|l|l|l|l|l|l|}
\hline InterteXto & Uberaba & UFTM & $\begin{array}{l}\text { v. 3 } \\
\text { n. } 1\end{array}$ & p. 24-47 & 2010 - jan. / jun. & ISSN 1981-0601 \\
\hline
\end{tabular}

prévios dos alunos para solução de problemas de leitura. Nesse sentido, a observação do suporte é colocada pelo autor (2007) como aspecto fundamental para estabelecer as tão necessárias relações entre os conhecimentos textuais e os gêneros do discurso.

Quanto à utilização de gêneros que são apresentados no livro didático fragmentados, como ocorre com os gêneros literários e também com o gênero tirinha, Pietri (2007, p. 73) indica que estes devem ser fragmentados em estratégias de leitura e não em estratégias de superficialização ${ }^{13}$ : "Isso pode ser realizado com a elaboração de questões e a construção de hipóteses que sejam úteis para a compreensão de outras partes do texto." Em outras palavras as hipóteses de leitura criadas nesse "jogo de mostrar e revelar" não se deterão somente ao aspecto materializado e apresentado em sala de aula (fragmentos), mas irão em direção a obra como um todo.

A partir dessas estratégias compreendemos, assim como Pietri (2007), e a partir das indicações dos PCN's (1998) e CBC-MG (2005), que para as aulas de leitura na escola os professores precisam buscar gêneros de qualidade que favoreçam o desenvolvimento de leitores proficientes, ou seja, buscar gêneros que sejam adequados a sala de aula do professor - aqueles que atendam aos interesses, competências e necessidades dos alunos -, bem como buscar aqueles que precisam de outros textos para serem compreendidos.

\section{2 - Pressupostos práticos}

A partir de um corpus textual composto por 20 tirinhas da personagem Aline do cartunista Adão Iturrusgarai da série "Aline Gorda" (2007) apresentaremos abaixo uma sugestão de como podemos utilizar o gênero tirinha no ensino de leitura.

Como atividade inicial realizaremos com os alunos algumas inferências

\footnotetext{
${ }^{13}$ Isso implica dizer que os gêneros no ensino são recortados para que sua leitura se torne mais fácil para os alunos.
} 


\begin{tabular}{|l|l|l|l|l|l|l|}
\hline InterteXto & Uberaba & UFTM & $\begin{array}{l}\text { v. 3 } \\
\text { n. } 1\end{array}$ & p. 24-47 & 2010 - jan. / jun. & ISSN 1981-0601 \\
\hline
\end{tabular}

de mundo quanto a tirinha e a personagem Aline. Perguntaremos livremente "quem/o que é Aline?" Essa pergunta sugere a formulação de muitas hipóteses: é uma mulher; é uma mulher que tem dois namorados, é uma jovem, é uma velha, é uma professora, entre outras - as respostas variarão de acordo com o conhecimento de mundo dos alunos. Apresentaremos em seguida a descrição da personagem Aline -

Aline é que é mulher de verdade. Trabalha fora de casa, odeia cozinhar e arrumar a casa e tem DOIS maridos. Ela divide a cama com Otto e Pedro. Os três se amam, mas isso não impede que Aline procure diversão fora do lar. Dizem as más línguas que Aline é ninfomaníaca, tarada sexual. Já as boas línguas preferem dizer que ela é uma mulher normal e simplesmente "dá vazão livre aos seus instintos sexuais (ITURRUSGARAI, 2007, contracapa).

- e algumas imagens de personagens recortadas de tirinhas que utilizaremos a posteriori (Imagem 1). Os alunos deverão unir a descrição textual de Aline com a sua imagem ${ }^{14}$.

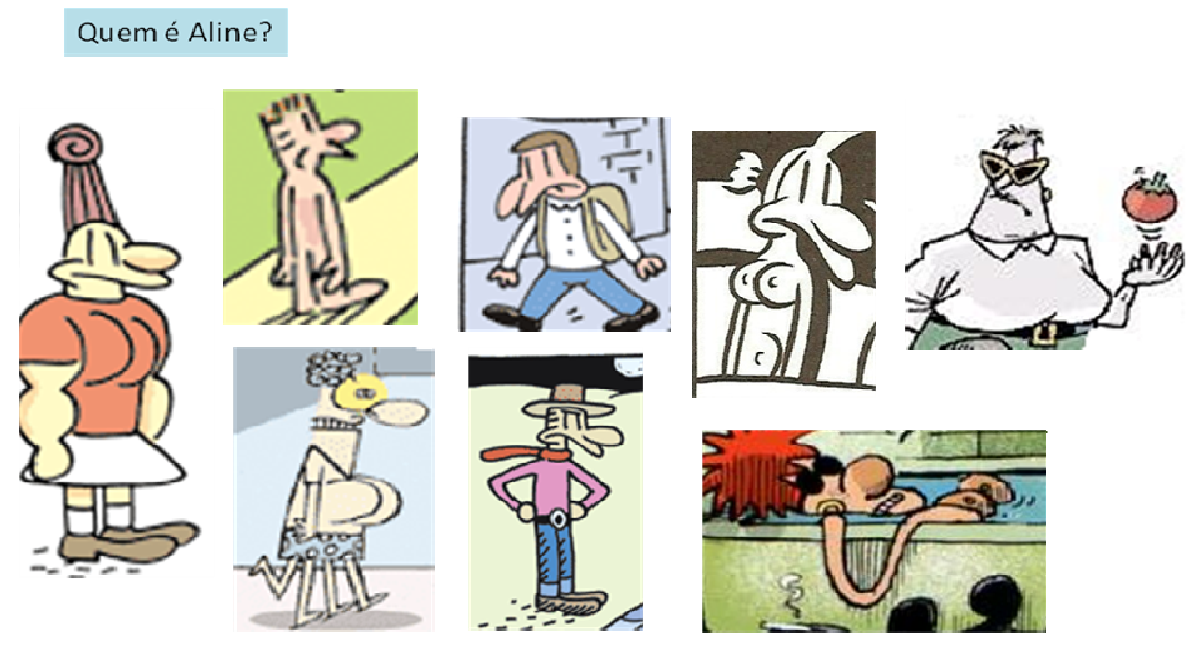

${ }^{14}$ Aqui exercitaremos a capacidade dos alunos de realizar inferências. Tal termo, como indica Koch \& Travaglia (2006, p. 79), "é a operação pela qual, utilizando seu conhecimento de mundo, o receptor (leitor/ouvinte) de um texto estabelece uma relação não explícita entre dois elementos (normalmente frases ou trechos) deste texto que ele busca compreender e interpretar; ou, então, entre segmentos de texto e os conhecimentos necessários para sua compreensão." 


\begin{tabular}{|l|l|l|l|l|l|l|}
\hline InterteXto & Uberaba & UFTM & $\begin{array}{l}\text { v. 3 } \\
\text { n. } 1\end{array}$ & p. 24-47 & 2010 - jan. / jun. & ISSN 1981-0601 \\
\hline
\end{tabular}

(Imagem 1 - Personagens de tiras.)

Perguntaremos de novo "quem é Aline?". Para respondermos essa pergunta apresentaremos aos alunos mais alguns personagens de tirinhas nessa ordem: Adôn, Laerton, Angel Villa e Glauquito (Imagem 2) -, dizendo que esses personagens de "Los 3 amigos" são autobiográficos e que refletem as características estéticas das tirinhas de seus cartunistas.

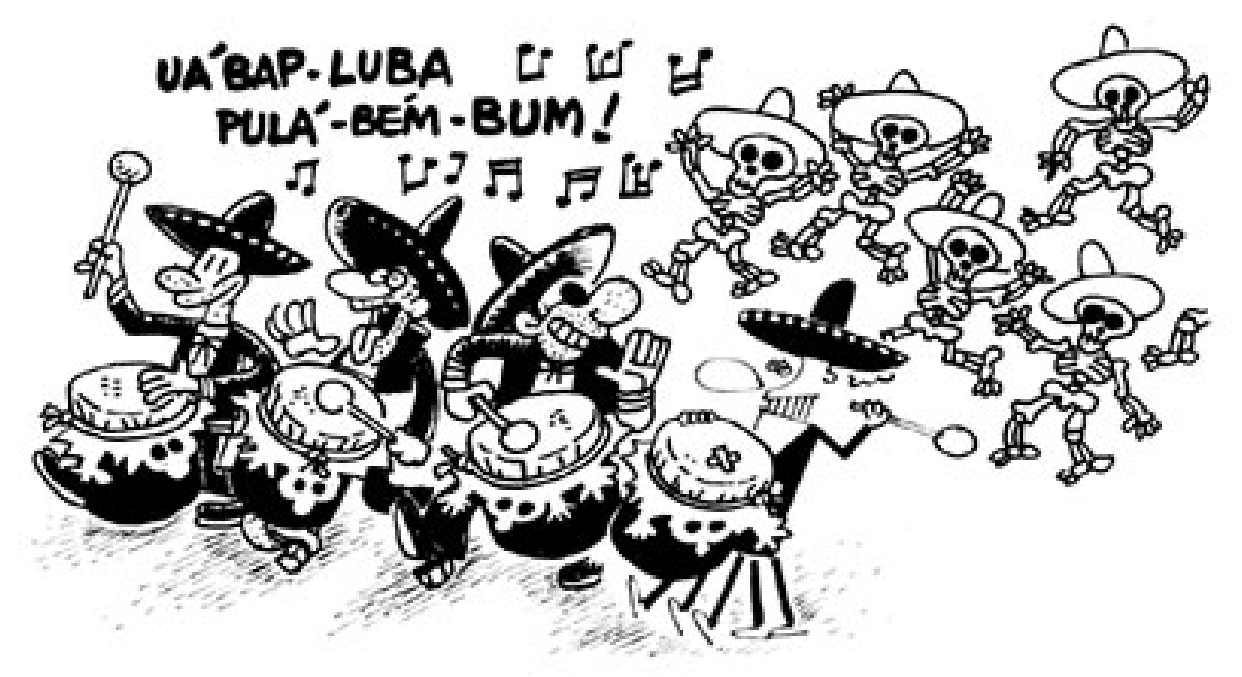

(Imagem 2 - Los tres amigos)

Junto com esses personagens apresentaremos também trechos de uma entrevista com os artistas citados ${ }^{15}$.

Após esse procedimento perguntaremos de novo: "quem é Aline?" e ainda "quem é o autor de das tirinhas de Aline?" Com essa pergunta outras hipóteses serão formadas e/ou confirmadas pelos alunos. Apresentaremos, então as 8 tirinhas de onde as imagens de personagens foram retiradas (Imagem 3, 4, 5, 6, 7, 8, 9, 10). Os alunos deverão associar as informações da

15 Conferir a entrevista na integra no endereço eletrônico: http://www.los3amigos.com.br/quadrinhos/entrevista-na-revista-sexy . 


\begin{tabular}{|l|l|l|l|l|l|l|}
\hline InterteXto & Uberaba & UFTM & $\begin{array}{l}\text { v. 3 } \\
\text { n. } 1\end{array}$ & p. 24-47 & 2010 - jan. / jun. & ISSN 1981-0601 \\
\hline
\end{tabular}

entrevista e dos "los tres amigos" para chegar à identificação da autoria e dos títulos das tirinhas.
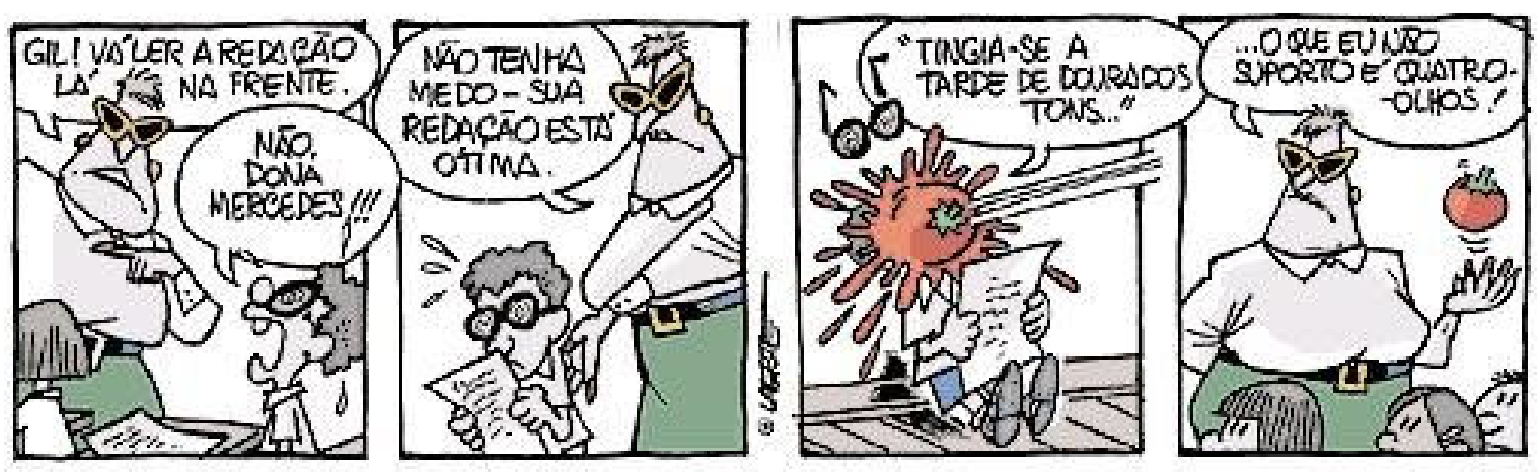

(Imagem 3 - LAERTE, 2009, on line)
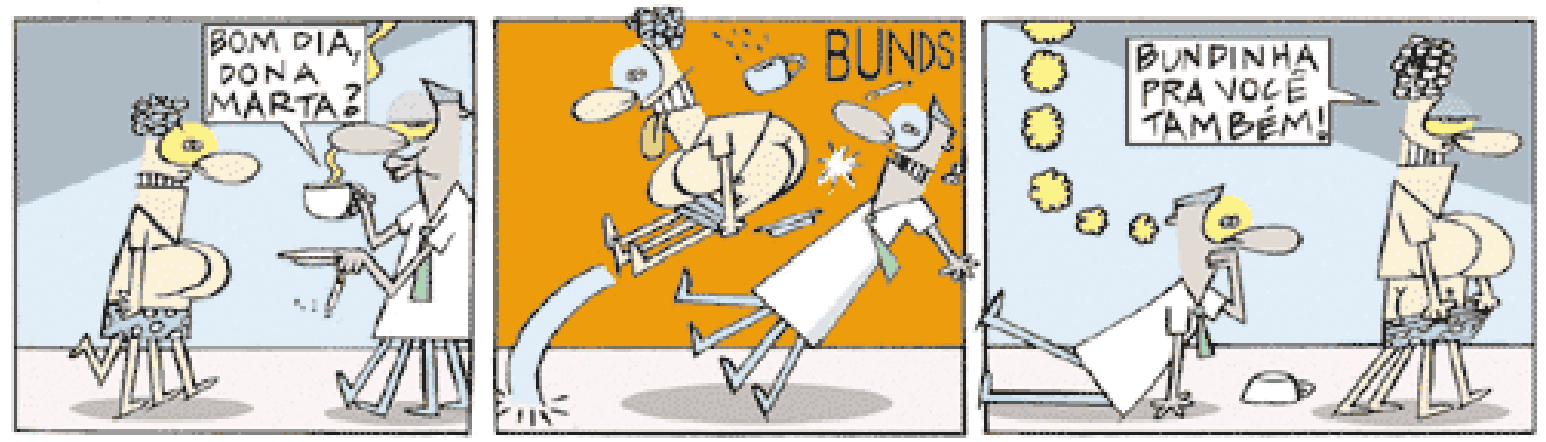

(Imagem 4 - GLAUCO, 2009, on line)
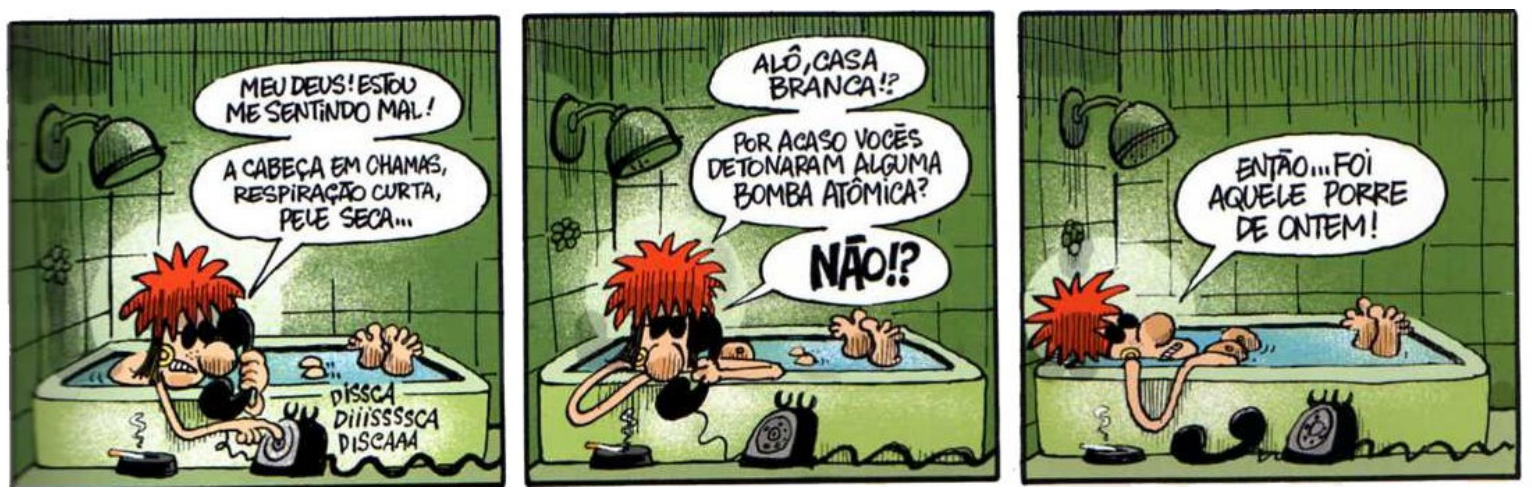

(Imagem 5 - ANGELI, 2001, p. 7) 


\begin{tabular}{|l|l|l|l|l|l|l|}
\hline InterteXto & Uberaba & UFTM & $\begin{array}{l}\text { v. 3 } \\
\text { n. } 1\end{array}$ & p. 24-47 & 2010 - jan. / jun. & ISSN 1981-0601 \\
\hline
\end{tabular}
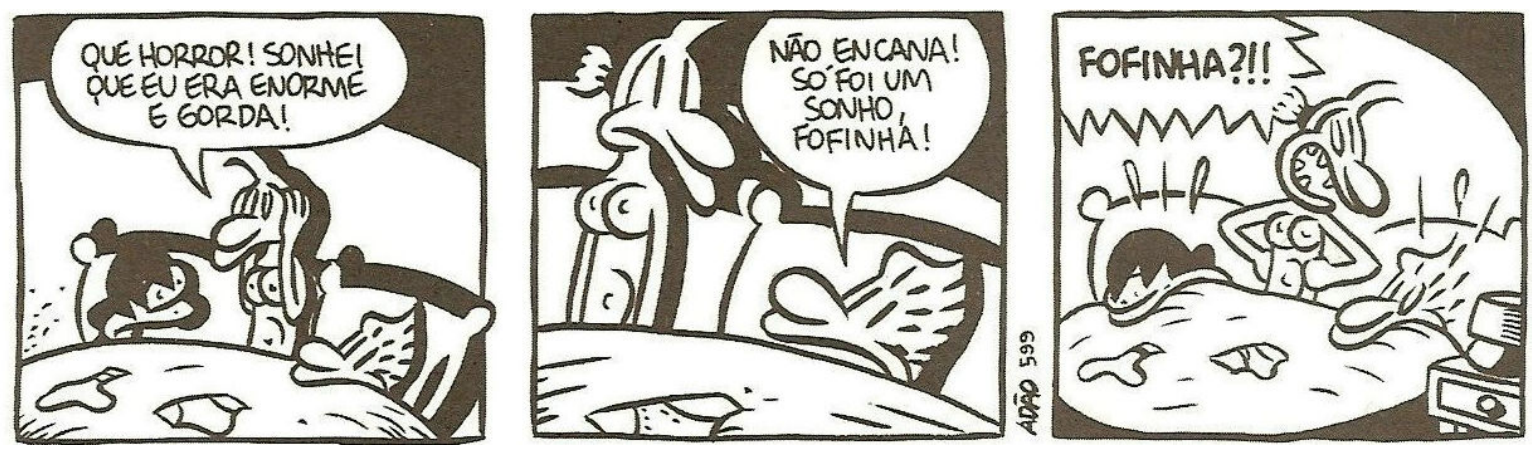

(Imagem 6 - ITURRUSGARAI, 2007, p. 92)
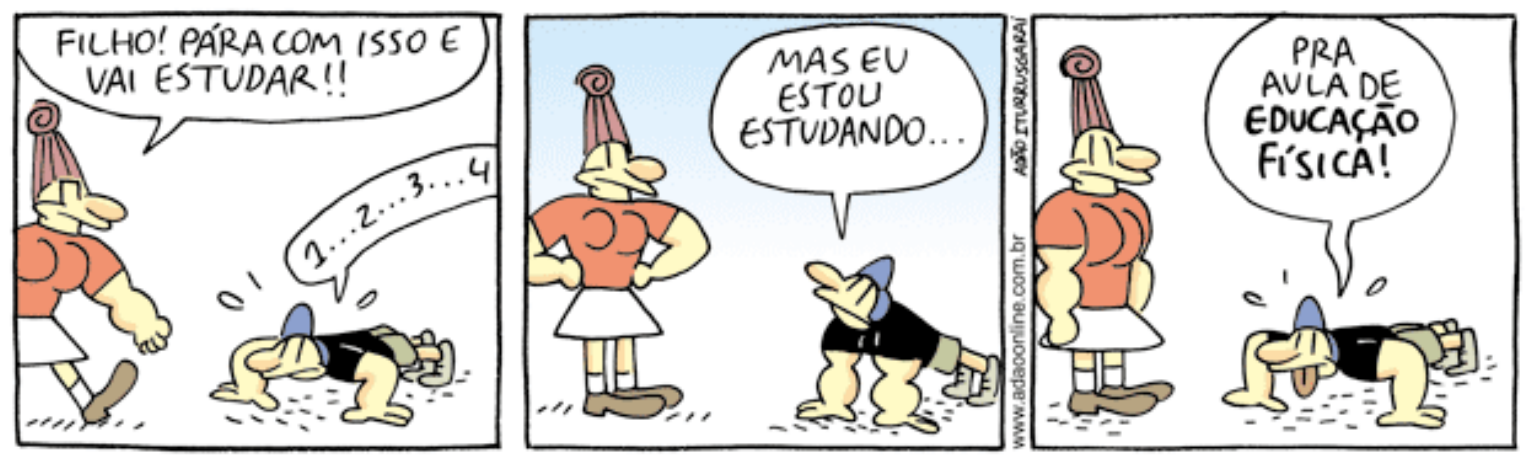

(Imagem 7 - ITURRUSGARAI, 2009, on line)
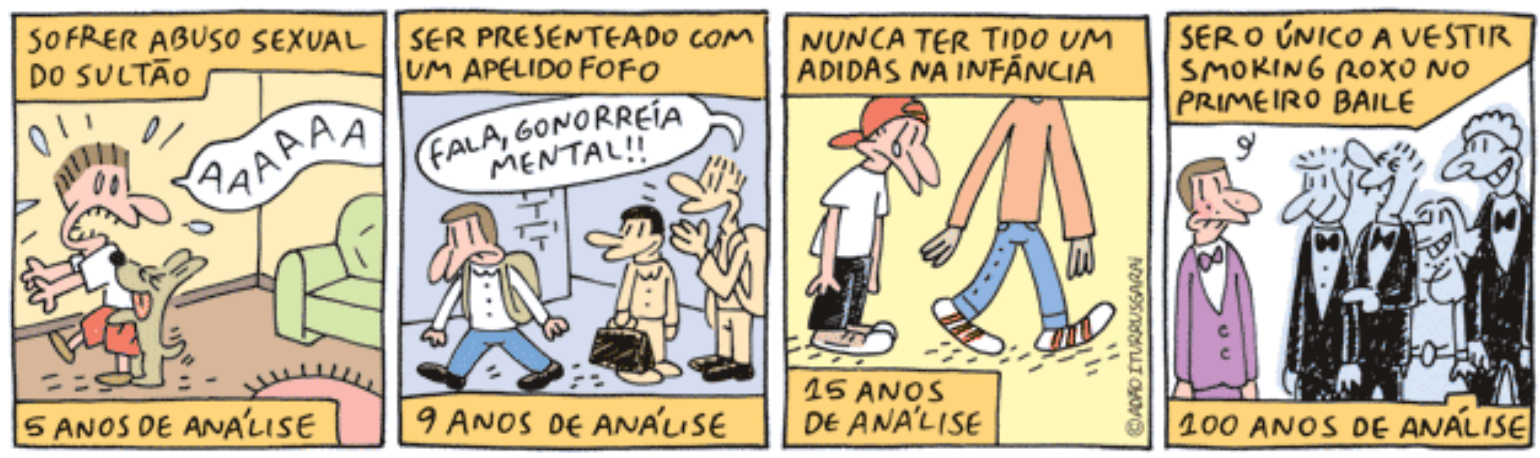

(Imagem 8 - ITURRUSGARAI, 2009, on line) 


\begin{tabular}{|l|l|l|l|l|l|l|}
\hline InterteXto & Uberaba & UFTM & $\begin{array}{l}\text { v. 3 } \\
\text { n. } 1\end{array}$ & p. 24-47 & 2010 - jan. / jun. & ISSN 1981-0601 \\
\hline
\end{tabular}
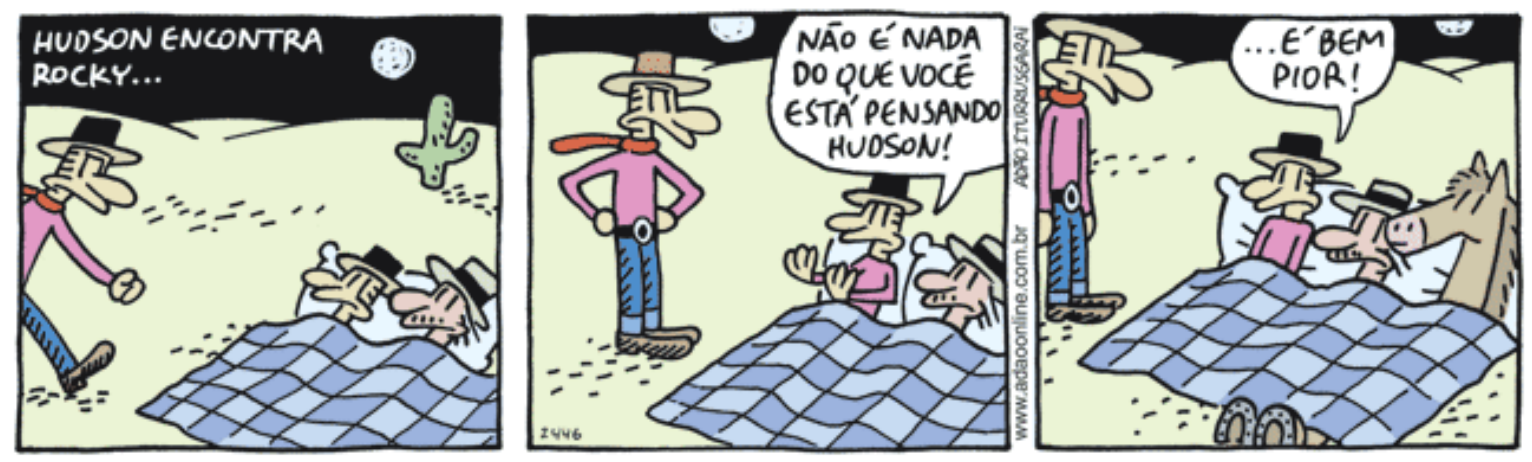

(Imagem 9 - ITURRUSGARAI, 2009, on line)
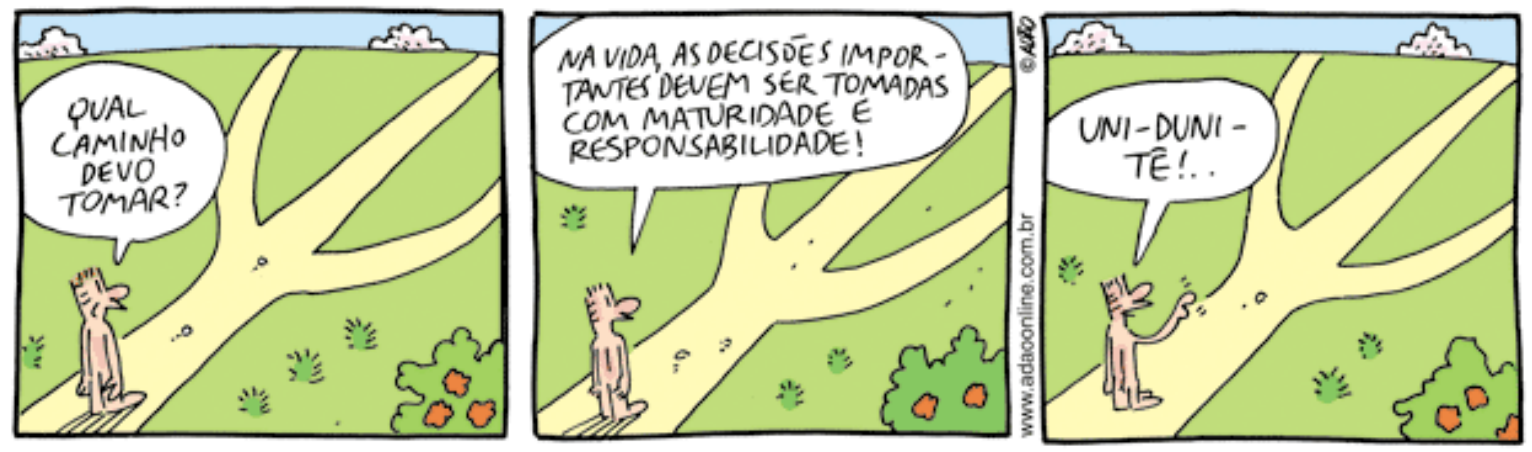

(Imagem 10 - ITURRUSGARAI, 2009, on line)

Perguntaremos novamente "quem é o autor de Aline? Que outras tirinhas o autor de Aline fez?" Ao analisarmos o traço específico do autor de Aline veremos que outras tiras (das 8 apresentadas) possuem o mesmo estilo de desenho da personagem Aline, o que nos indicará que este autor possui outras tiras além de Aline (Imagem 11). 


\begin{tabular}{|l|l|l|l|l|l|l|}
\hline InterteXto & Uberaba & UFTM & $\begin{array}{l}\text { v. 3 } \\
\text { n. } 1\end{array}$ & p. 24-47 & 2010 - jan. / jun. & ISSN 1981-0601 \\
\hline
\end{tabular}

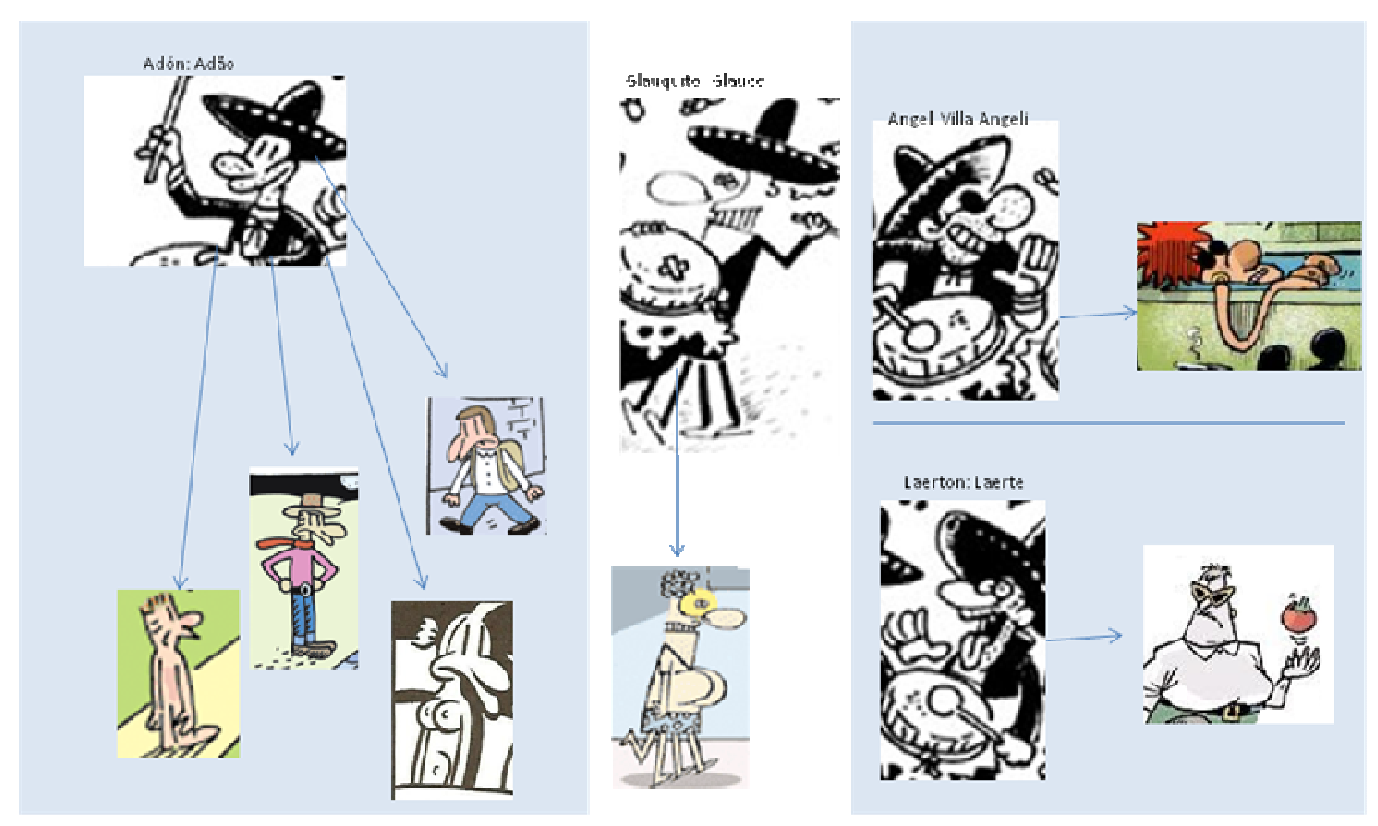

(Imagem 11 - Inferências realizadas entre personagens, tiras e autores)

Resta-nos, então, a pergunta: se Aline é escrita por Adão, quem escreveu as outras tirinhas? Para facilitar essa tarefa apresentaremos os títulos das tirinhas juntamente com um resumo das tiras mostradas:

\section{Condomínio:}

Dona Mercedes mora no condomínio a muitos anos. Ela é uma professora nada ortodoxa.

\section{Rocky e Hudson:}

Rochy e Hudson são corajosos, saíram do armário em pleno velho oeste habitado por caubóis durões. Até hoje Jonh Wayne estremece na sua tumba.

\section{Dona Marta:}

Ela foi educada à maneira antiga e, tanto esperou seu homem, que acabou ficando para titia. Quando viu que não arrumaria namorado, passou para o ataque. Aliás, Dona Marta canta qualquer um. Pode ser o chefe, o boy do escritório, o entregador de pizza ou o salva-vidas. Mesmo não tendo o corpo em forma, ela se acha a mais gostosa do 


\begin{tabular}{|l|l|l|l|l|l|l|}
\hline InterteXto & Uberaba & UFTM & $\begin{array}{l}\text { v. 3 } \\
\text { n. } 1\end{array}$ & p. 24-47 & 2010 - jan. / jun. & ISSN 1981-0601 \\
\hline
\end{tabular}

planeta.

\section{Rê Bordosa "A mulher esponja":}

"O sol nasce para todos. Menos para Rê Bordosa que preferiu refugia-se na escuridão da vida noturna. Conha que misturado com cerveja, vodca digerida com cocaína, sexo com sentimento de culpa. Por isso sem pestanejar, trocar seus verdes anos pelo roxo das olheiras. Era bonitinha quando menina, saborosa na adolescência e hoje usa meias para esconder as primeiras estrias. Mas mesmo com tudo isso não se sente diferente das outras mulheres afinal, ir sozinha a um bar dá tanto trabalho quanto criar um filho" (ANGELI, 2001, p. 2).

\section{Família Bíceps:}

A família Bíceps é uma moderna família, saudável e forte até demais.

"+ ou - anos de análises":

Quem não precisa de uma análise hoje em dia?

\section{La vie En Rose:}

Reflexões da vida moderna, nada profundas ou perturbadoras.

A partir dessa exposição veremos que hipóteses de leitura dos alunos serão confirmadas (ou não). Pela junção de informações e/ou conhecimentos de mundo os alunos perceberão que o cartunista Adão Iturrusgarai escreveu outras tirinhas como Rochy e Hudson, La vie en Rose e "+ ou - anos de análise".

Seguindo com as perguntas de leitura, iremos analisar com os alunos as tirinhas da série "Aline Gorda"16. Perguntaremos oralmente:

1) Conhecendo Aline, que tipo de histórias da personagem pode

\footnotetext{
${ }^{16}$ A série de tiras "Aline Gorda" pode ser vista na íntegra no livro Aline: Tensão pré-monstrual, de Adão Iturrusgarai (2007) editado pela editora LP\&M Pocket. Este livro é facilmente encontrado nas livrarias e em bancas de revistas.
} 


\begin{tabular}{|l|l|l|l|l|l|l|}
\hline InterteXto & Uberaba & UFTM & $\begin{array}{l}\text { v. 3 } \\
\text { n. } 1\end{array}$ & p. 24-47 & 2010 - jan. / jun. & ISSN 1981-0601 \\
\hline
\end{tabular}

aparecer com o tema "Aline Gorda?

2) Como alguém descobre que está gordo?

3) O que é preciso fazer para perder peso?

4) Como Aline descobriu que estava gorda? Ela gostou de saber disso?

5) O que ela fez para perder peso?

Com essas perguntas analisaremos primeiramente a compreensão do material lingüístico dado, a partir de estratégias de decodificação (perguntas 4 e 5) de estratégias cognitivas de leitura (perguntas 1, 2, 3).

As perguntas seguintes pretendem incitar os alunos a decodificarem 0 material lingüístico não-verbal das tirinhas, por exemplo:

1) Pedro gosta de ver Aline gorda? E Otto?

Com algumas das tirinhas da série "Aline Gorda" pediremos para os alunos completarem algumas $\operatorname{vinhetas}^{17}$ da tirinha pensando nas características de Aline, da tirinha Aline e dos efeitos de humor dessa tira (Imagem 12, 13, 14, 15). Essa técnica busca incentivar os alunos a produzirem, ainda que parcialmente, o gênero tirinha, além, é claro, de ser um meio de confirmar ou não as hipóteses de leitura formuladas até o momento.
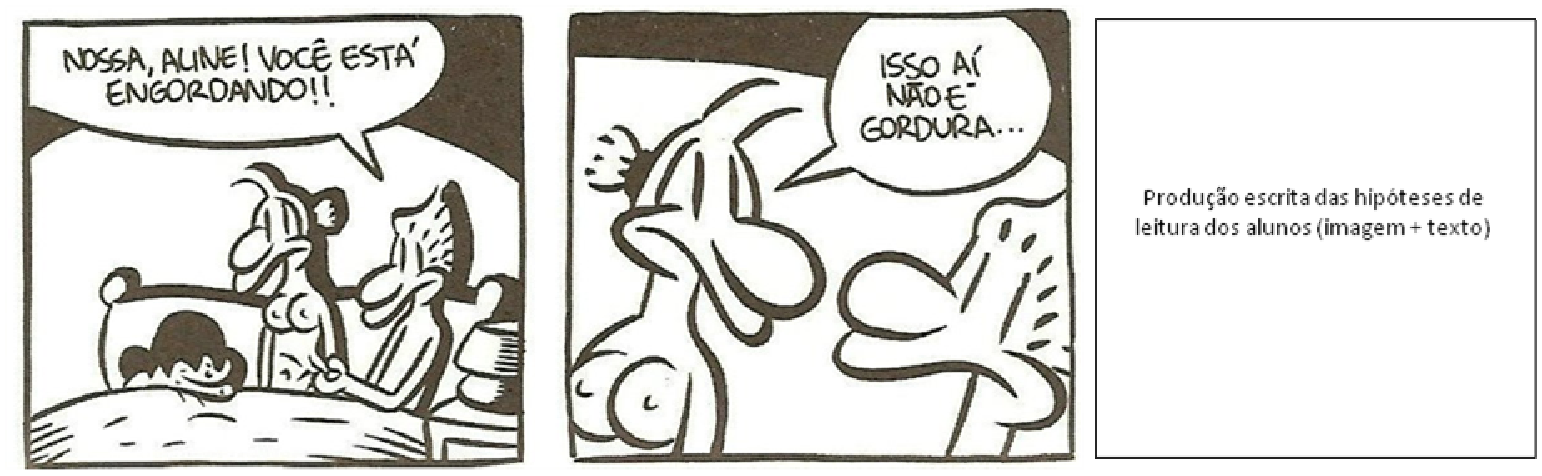

\footnotetext{
17 Segundo Ramos (2009) vinheta é um dos quadros que compõem a tira que pode ou não ser preenchida com requadro (linha de contorno da vinheta).
} 


\begin{tabular}{|l|l|l|l|l|l|l|}
\hline InterteXto & Uberaba & UFTM & $\begin{array}{l}\text { v. 3 } \\
\text { n. } 1\end{array}$ & p. 24-47 & 2010 - jan. / jun. & ISSN 1981-0601 \\
\hline
\end{tabular}

(Imagem 12 - ITURRUSGARAI, 2007, p. 92, editado)
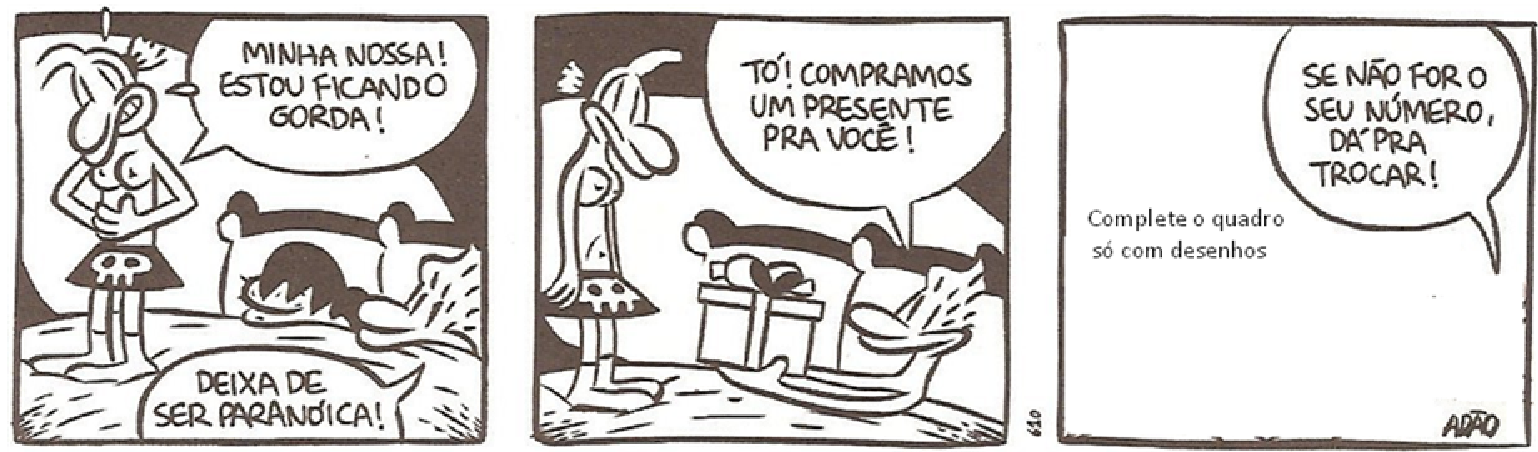

(Imagem 13 - ITURRUSGARAI, 2007, p. 97, editado)
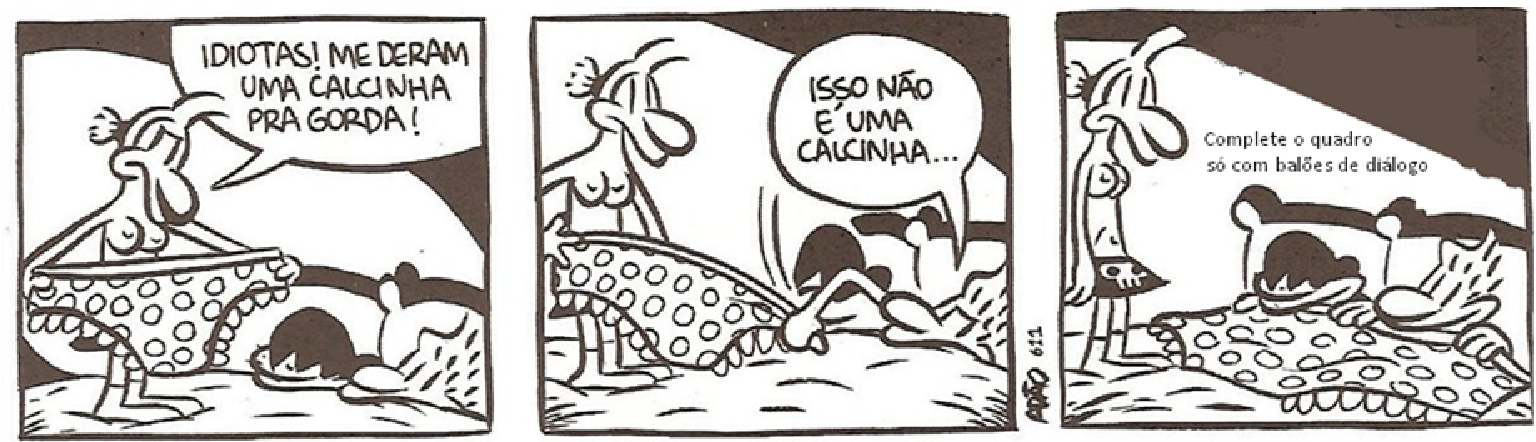

(Imagem 14 - ITURRUSGARAI, 2007, p. 98, editado)
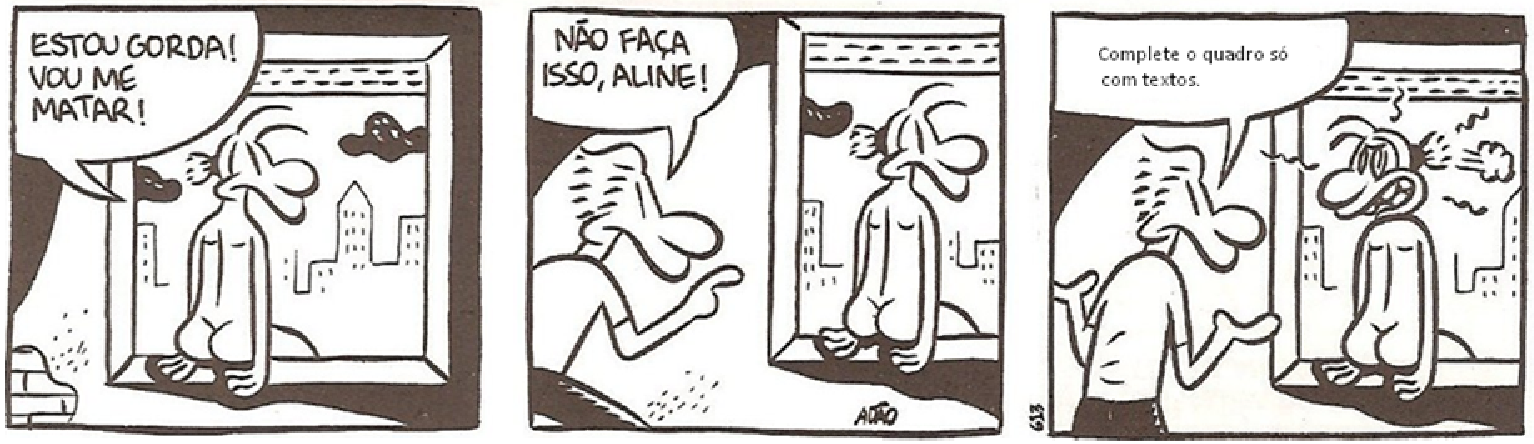

(Imagem 15 - ITURRUSGARAI, 2007, p. 98, editado)

Prosseguindo com o jogo de "mostrar e revelar" apresentaremos aos 


\begin{tabular}{|l|l|l|l|l|l|l|}
\hline InterteXto & Uberaba & UFTM & $\begin{array}{l}\text { v. 3 } \\
\text { n. } 1\end{array}$ & p. 24-47 & 2010 - jan. / jun. & ISSN 1981-0601 \\
\hline
\end{tabular}

alunos algumas das tirinhas de Aline que abordam temas do cotidiano ${ }^{18}$ como:

1) Há top model de sucesso que são magras, Aline quer ser magra. A que top model Aline se refere em sua história?

2) Há revistas masculinas que abordam (ou não) as mulheres acima do peso?

A que revistas masculinas de mulheres gordas Otto e Pedro se referem na história? Existem outras? Quais?

3) Há diversas dietas para emagrecer. Que dietas podem fazer Aline emagrecer? Aline gosta de fazer dietas?

No tópico seguinte, refletiremos com os alunos sobre algumas especificidades do gênero tirinha, tais como:

1) De quem é a voz no retângulo superior das vinhetas da tirinha Aline? Que intenção tem essa voz? ${ }^{19}$

2) Por que em alguns momentos as vinhetas da tirinha de Aline possuem tamanhos diferentes ${ }^{20}$

3) Por que há um contorno diferente nos balões que representam os sonhos de Aline ${ }^{21}$

4) Por que a tirinha de Aline na série "Aline Gorda" estão em preto e branco? ${ }^{22}$

\footnotetext{
${ }^{18}$ Com essas perguntas abordamos a leitura enquanto processo cognitivo (perguntas 1,2 e 3 ) e também enquanto processo de decodificação (perguntas 2 e 3 ).

${ }^{19}$ Quem fala no retângulo superior das vinhetas é o narrador, que pode ter muitas intenções ao se pronunciar.

${ }_{20}$ Isso ocorre, segundo Ramos (2009), pois as histórias em quadrinho tentam demonstrar o tempo narrativo utilizando vinhetas maiores (para indicar que as ações que ocorreram ali demoraram algum tempo para acontecer) ou vinhetas menores (para indicar que as ações que ocorreram ali não demoraram muito para ocorrer). Vale ressaltar ainda que vinhetas de um mesmo tamanho sugerem que o tempo narrativo se passou de maneira igualitária.

${ }^{21}$ Os balões e o formato de suas letras (em negrito, sinuoso, entre outros), segundo Ramos (2009) podem indicam emoções ou sensações dos personagens. Um balão com pontinhos e nuvens indica que o personagem está sonhando ou pensando aquela situação, ou seja, aquilo se processa somente em sua mente e não na mente de outros personagens.

${ }^{22}$ Com esta pergunta, incitaremos os alunos a se questionarem sobre o suporte das tirinhas de Aline. A partir de suas observações, os alunos concluirão que sendo editado por pela LP\&M Pocket os livros possuem um conceito agregado ao seu suporte: devem ser baratos e
} 


\begin{tabular}{|l|l|l|l|l|l|l|}
\hline InterteXto & Uberaba & UFTM & $\begin{array}{l}\text { v. 3 } \\
\text { n. } 1\end{array}$ & p. 24-47 & 2010 - jan. / jun. & ISSN 1981-0601 \\
\hline
\end{tabular}

5) Ao observar as imagens 16, 17 e 18 ${ }^{23}$, você consegue ver alguma semelhança de composição tipológica entre esses textos com as tirinhas de Aline? Nas tirinhas de Aline há que tipo de composição tipológica? Narração? Descrição? Argumentação? Exposição? Injunção? Onde aparecem? Por que você acha que elas apareceram ${ }^{24}$

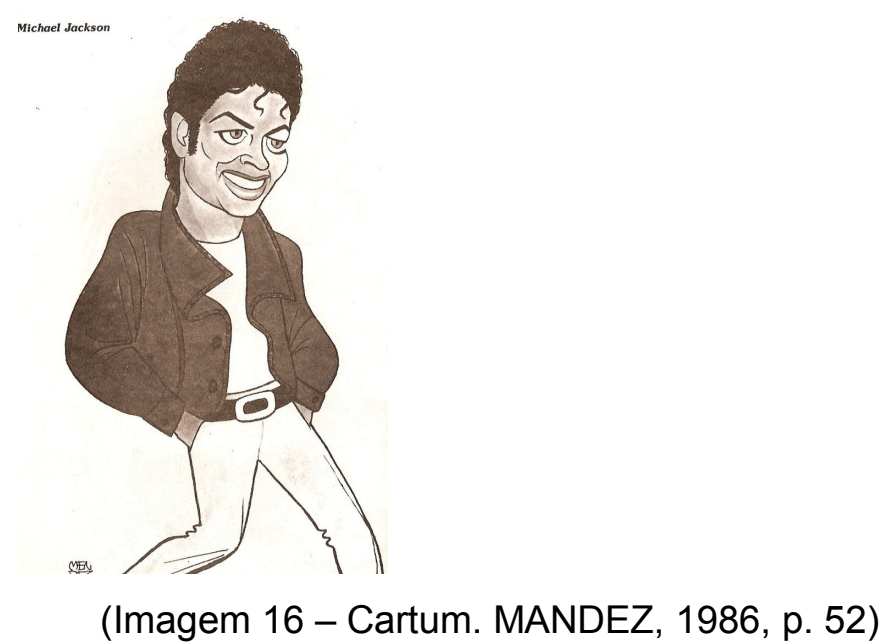

acessíveis ao público. Devido a isso, então, as tiras de Aline, que em outros casos são coloridas, formam impressas em preto e branco para minimizar o custeio do livro.

${ }^{23}$ o cartum (imagem 18), que apresenta tipicamente o tipo textual narrativo e/ou descritivo uma vez que tem como função comunicativa básica relatar os fatos do cotidiano atemporais de maneira bem humorada; a caricatura (imagem 16), que apresenta tipicamente o tipo textual descritivo uma vez que tem como função comunicativa básica descrever personalidades da sociedade; e a charge (imagem 17), que apresenta tipicamente o tipo textual descritivo (pois relata uma notícia temporal em forma de imagem), narrativo (pois relata uma história do cotidiano) e argumentativo (pois quer nos convencer sobre alguma idéia ou fato). A tirinha, como podemos observar no corpus de "Aline Gorda" (imagem 6), se utiliza principalmente desses tipos textuais em sua composição - normalmente não costuma utilizar o tipo argumentativo, mas pode se valer desse recurso para narrar ou descrever uma situação.

${ }^{24} \mathrm{Com}$ esta pergunta, estamos incentivando os alunos a buscarem as respostas para as questões de leitura através da interação entre o autor dos textos e seus leitores. Com isso, também, estamos favorecendo a análise da composição do gênero tirinha e se sua função social na sociedade. 


\begin{tabular}{|l|l|l|l|l|l|l|}
\hline InterteXto & Uberaba & UFTM & $\begin{array}{l}\text { v. 3 } \\
\text { n. } 1\end{array}$ & p. 24-47 & 2010 - jan. / jun. & ISSN 1981-0601 \\
\hline
\end{tabular}

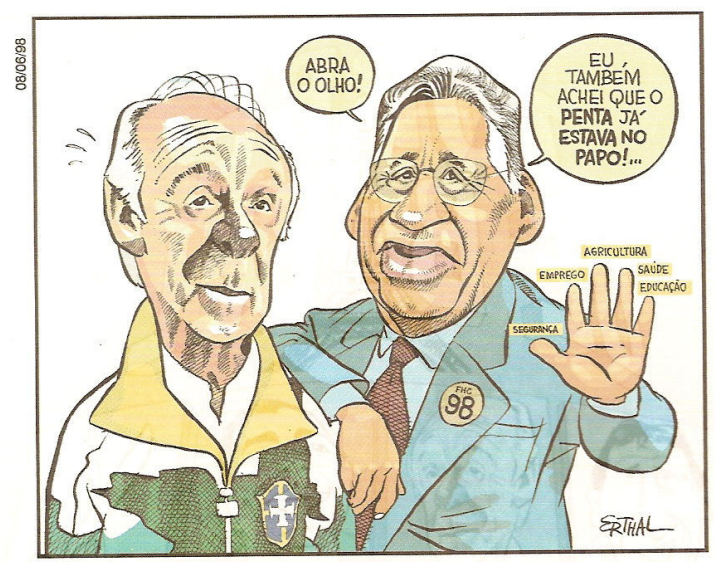

(Imagem 17 - Charge. ERTHAL, 1998, p. 67)

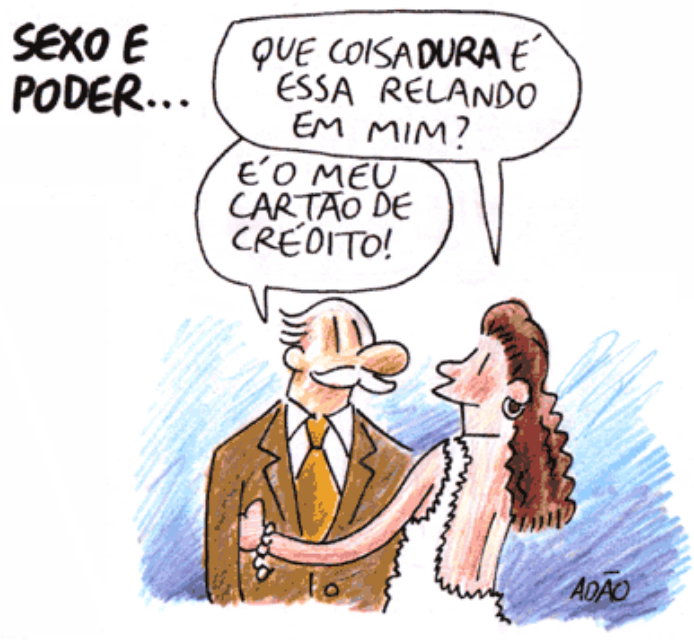

(Imagem 18 - Cartum. ITURRUSGARAI, 2009, on line)

A partir desse panorama de estratégias didáticas esperamos ter indicado como podemos ensinar a leitura por meio do gênero tirinha em aulas de língua portuguesa. Na última seção iremos, portanto, tecer as nossas considerações finais sobre o assunto.

\section{Considerações Finais}

A partir das considerações teóricas sobre gêneros de Bakhtin (2000), 


\begin{tabular}{|l|l|l|l|l|l|l|}
\hline InterteXto & Uberaba & UFTM & $\begin{array}{l}\text { v. 3 } \\
\text { n. } 1\end{array}$ & p. 24-47 & 2010 - jan. / jun. & ISSN 1981-0601 \\
\hline
\end{tabular}

Todorov (1980) e Bazerman (2006a; 2006b) e das indicações metodológicas sobre o ensino de leitura propostas por Moita Lopes (1996) e Pietri (2007) que indicam a construção e verificação de hipóteses de leitura como recursos didáticos-pedagógicos para o trato com a leitura e com os gêneros em sala de aula - apresentamos em nossa exposição uma sugestão didática para o ensino de leitura a partir de um corpus textual composto por 20 tirinhas do cartunista Adão Iturrusgarai (2007). Nossa sugestão consistiu nos seguintes passos: construção e verificação de hipóteses de leitura sobre o nome da tirinha e da personagem central da mesma (Aline); identificação do autor da tira em meio a outras tiras e outros autores (por meio de seu estilo de desenho característico); construção e verificação de hipóteses sobre a série "Aline Gorda"; produção escrita de partes da tirinha como meio de construção de hipóteses de leitura; reflexão sobre outros temas que surgiram na tirinha "Aline Gorda" e que necessitavam de outros conhecimentos de mundo para resolvê-los (o que sugere aos alunos uma pesquisa de campo); e algumas reflexões e comparações entre a tirinha e outros gêneros discursivos, tais como a caricatura, a charge e o cartum a fim de evidenciar-se as características composicionais do gênero tirinha.

Nossas iniciativas, então, se mostraram relevantes, pois atualmente, como discorremos em nosso artigo, os professores, de forma geral, carecem de instrumentos didáticos que os façam atuar com os gêneros multimodais em sala de aula e com a leitura enquanto fenômeno processual e de interação. Cabe ressaltamos aqui, portanto, que nossas indicações correspondem somente a uma sugestão metodológica que não deve ser seguida sem a necessária reflexão do professor sobre que gênero e tema este pode levar para sua sala de aula.

\section{Referências}




\begin{tabular}{|l|l|l|l|l|l|l|}
\hline InterteXto & Uberaba & UFTM & $\begin{array}{l}\text { v. 3 } \\
\text { n. } 1\end{array}$ & p. 24-47 & 2010 - jan. / jun. & ISSN 1981-0601 \\
\hline
\end{tabular}

ANGELI. Sobras completas 3: Rê Bordosa - vida e obra da porraloca. São Paulo: Devir - Jacaranda, 2001.

BAKHTIN, Mikhail. Os gêneros discursivos. In: Estética da Criação Verbal. São Paulo: Martins Fontes, 2000. p. 279-326.

BAZERMAN, Charles. Gênero, agência e escrita. Tradução e adaptação Judith Chambliss Hoffnagel. São Paulo: Cortez, 2006a. p. 23-34.

BAZERMAN, Charles. Gêneros textuais, tipificação e interação. $2^{\mathrm{a} E d}$.

Tradução e adaptação Judith Chambliss Hoffnagel. São Paulo: Cortez, 2006b. p. $19-61$.

BONINO. Rachel. Onomatopéia, imagem e ação. In: REVISTA EDUCAÇÃO. Ano 12, n 144, Ed. Seguimento, Abr. 2009. p. 24-59.

CBC - Conteúdos Básicos Comuns. Governo de Minas Gerais. SEE-MG, 2005. ERTHAL, Júlio. Fatores de Risco. Rio de Janeiro: Ediouro, 1998.

GLAUCO. Dona Marta. Disponível em:

http://www2.uol.com.br/glauco/donamarta.shtml . Acesso em: 25 Nov. 2009. ITURRUSGARAI, Adão. Aline 2: TPM - Tensão Pré-mostrual. Porto Alegre: L\&PM, 2007. 92-103.

ITURRUSGARAI. O mundo maravilho de Adão Iturrusgarai. Disponível em: http://adao.blog.uol.com.br/ . Acesso em 25 Nov. 2009. KOCH, I. G. V.; TRAVAGLIA, Luiz Carlos. A coerência textual. $17^{\circ}$ Ed. São Paulo: Contexto, 2006.

$\mathrm{KOCH}$, I. G. V. Desvendando os segredos do texto. $5^{\mathrm{a}}$ Ed. São Paulo: Cortez, 2006.

LAERTE. Dona Mercedes. Disponível em http://chermontlopolis.wordpress.com/2006/10/13/dona-mercedes/ . Aceso em 25 Nov. 2009.

MARCUSCHI, Luis Antônio. Gêneros textuais e ensino. Editora Lucerna: Rio de Janeiro, 2002. p. 19-36.

MARCUSCHI, Luis Antônio. Produção textual, análise de gêneros e compreensão. São Paulo: Parábola Editorial, 2008. p. 173-186. 


\begin{tabular}{|l|l|l|l|l|l|l|}
\hline InterteXto & Uberaba & UFTM & $\begin{array}{l}\text { v. 3 } \\
\text { n. } 1\end{array}$ & p. 24-47 & 2010 - jan. / jun. & ISSN 1981-0601 \\
\hline
\end{tabular}

MCCLOUD, Scott. Desvendando os quadrinhos. Tradução Hélcio de Carvalho; Marisa do Nascimento Paro. São Paulo: Makron Books, 1995. MENDES, Mario. Caricaturas e Caricaturados. [S.I]: Editora, Tecnoprint S.A , 1986.

MOITALOPES, Luiz Paulo da. Oficina de lingüística aplicada - a natureza social e educacional dos processos de ensino/aprendizagem de línguas. São Paulo: Mercado de Letras, 1996. p. 147-158.

PCN - Parâmetros Curriculares Nacionais. Ministério da Educação - MEC, 1998.

PIETRI, Émerson de. Práticas de leitura e elementos para a atuação docente. Rio de Janeiro: Lucerna, 2007. 96p.

RAMOS, Paulo. A leitura dos quadrinhos. São Paulo: Contexto, 2009.

SEXY. Entrevista com los três amigos. Disponível em:

http://www.los3amigos.com.br/quadrinhos/entrevista-na-revista-sexy . Acesso em: 29 Nov. 2009.

SOARES, Magda. Letramento um tema em três gêneros. $2^{a} E d$. Belo Horizonte: Autêntica, 2004.

TODOROV, T. A origem dos gêneros. In: TODOROV, T. Os gêneros do discurso. São Paulo: Martins Fontes, 1980. p. 43-58. 